\title{
Looking for emerging themes in medical humanities - some invitations to our readers
}

\section{H M Evans, D A Greaves}

\section{Readers are invited to write about what themes should shape the continuing development of medical humanities}

\section{Where are the people? I am their} leader-l ought to follow them."

$O^{0}$ cried Alexandre Ledru-Rollin during the 1848 revolution in France. ${ }^{1}$ Now it is a hazardous business for editors to conjecture about the parallels between their steering of a topical academic journal and a radical lawyer's directing of social uprising, and even the most indulgent and benevolent of our readers may be seriously alarmed at our possible editorial intentions, not to say delusions. So let us give an assurance that having — as we hope-by means of it secured the reader's undivided attention we will allow (indeed, encourage) the implied parallel to wither. The formal resemblance that interests us concerns, in any case, not editorial megalomania but the role of any journal which-if the position it occupies in its chosen field of inquiry is at all visible and conspicuous-has a responsibility to guide, or at least to illuminate, the path ahead.

The actual leadership involved is primarily exercised of course by the authors of the published papers. As editors we must select those papers; we can even hope to stimulate and encourage their production; but beyond these essentially supporting roles we are in the hands of our readers and our contributing writers. In this sense, and in this sense alone, we are conscious of Ledru-Rollin's diffident explanation as to why he was heading where he was heading.

This is after all only the seventh issue of Medical Humanities, but already the eclectic nature of its content bespeaks what is becoming an established pattern of eclectic interests among the readership and contributing writers: this journal reflects, we hope faithfully, the wide ranging mosaic of inquiries and perspectives which together constitute the medical humanities as a field of interest. A survey of the original papers published in the six issues to date shows something of the breadth of the field, and it was interesting to attempt (as we do here) to impose some sort of order, some sort of classification, on the collected papers. Two "health warnings" are in order, before we proceed. Firstly, our classification may reflect both what our contributors are interested in, and the interests of our reviewers and ourselves as editors-and the two sets of influences may not have been equally felt. Secondly, it is clear that other classifications are possible-perhaps we had better leave aside here the familiar feeling that classifications are natural and self evident when you produce them yourself, though arbitrary and subjective when other people do it.

Listing the apparent categories in descending order of size, we picked out the following. The largest category comprises broadly philosophical inquiries into central ideas in medicine and into the humanities' engagement with them. Altogether eleven individual papers are variously concerned with medicine and the arts, ${ }^{2}$ concepts of disease, illness, and healing, ${ }^{3}$ medicine as an art and as a science, ${ }^{45}$ aesthetic and ethical considerations in surgery, ${ }^{6-8}$ the technology driven conventionality of disease classifications and diagnoses, ${ }^{10}{ }^{10}$ the existential focus of clinical medicine, ${ }^{11}$ and the extent of chaos theory's relevance to medicine. ${ }^{12}$

The next largest category, with seven individual papers, comprises essays in literary criticism and exploration, including any lessons they may provide for clinical medicine. These include papers on short stories by Kafka ${ }^{13}$ and Chekhov, ${ }^{14}$ a play by Jules Romain, ${ }^{15}$ the Sherlock Holmes tales, ${ }^{16}$ Hamlet and depressive illness, ${ }^{17}$ medical syndromes in French nineteenth century fiction, ${ }^{18}$ and the lessons of television drama for clinical craft. ${ }^{19}$

Vying for third place is the category of papers devoted to medical education matters, with four papers, to which should be added the shorter papers on educational matters featuring in our regular "Education and debate" column. The longer papers include a report on the prior development of medical humanities in Argentina, ${ }^{20}$ structures and outcomes in medical humanities education, ${ }^{21}$ and the propriety or otherwise of the instrumental use of poetry in medical education. ${ }^{22}{ }^{23}$ This category is rivalled by the category of papers on the lessons of history, which variously cover dissection, ${ }^{24} 25$ and intriguing vignettes on the medical ethics of Erasmus, ${ }^{26}$ science and the imagination in the Age of Reason, ${ }^{27}$ and the letters of patients and doctors in two distinct centuries. ${ }^{28}$

A category which we might entitle "Cultural studies" also includes four papers, variously bringing differing combinations of fine art, literature, history, and philosophy to bear on a range of conditions and topics: anorexia nervosa, ${ }^{29}$ aging, ${ }^{30}$ body image and perceived bodily abnormalities, ${ }^{31}$ and distinguishing patients as persons. ${ }^{32}$

The remaining papers fall less easily into categories, and variously invite us to consider the importance of architecture and the built environment, ${ }^{33}{ }^{34}$ the application of humanities in clinical practice $^{35}$ including psychiatric practice, ${ }^{37}$ and the power of metaphors and images in (sometimes cathartic) writing of one's own. ${ }^{38-40}$ In addition we have included under the column title "Medicine through the novel" personal reactions to books that have been found influential by invited contributors. ${ }^{41-43}$

Now simply describing apparent clusters is of course interesting, but where does it leave us? A more ambitious, though of course more awkward, question than simply "Where are you going?" is "Why are you going there?" In our case, the question is not "What happen to be . .?" but rather "What ought to be the emergent themes of inquiry within the medical humanities?" This is not to imply that there is anything wrong with the interests that seem to emerge as prevalent so far. To reiterate, a topical academic journal's role must begin by being a reflection of the interests and concerns of its readership; the obvious alternative is bankruptcy and oblivion! Yet, having said this, it is arguably also a role for such a journal to influence and selectively to encourage some inquiries rather than others. This is not simply a matter of publishing only those papers which are sufficiently well argued and well written as to satisfy the reviewers and referees-although of course that is always necessary. Beyond the matter of sheer publishability of individual papers, there is the question of the directions in which different inquiries may lead.

At a very general level (albeit stemming from parochial editorial interests) it would be natural for this journal to encourage "open" rather than "closed" inquiries; that is to say, those inquiries which will lead to further development, those papers which will provoke readers into replying-ideally through further papers of their own. To an extent this has already happened, particularly in the 
case of papers concerning literature, metaphor, and education. Of course there must be more to this than "durability" alone. Inquiries must, in addition to simply rumbling along, lead in directions that are fruitful for the development of the whole field of study. Discerning what those directions might be is an exciting but perilous business, and is bound to be controversial: different conceptions of the field of study will engender different views as what could count as "fruitful development".

Just how perilous this is, at a rather general level concerning the institutional "positioning" of medical humanities inquiries in relation to medical ethics, is explored in Pattison's paper in the current issue- a provocative challenge to us to avoid the pitfalls of "professionalising" medical humanities, and an equally provocative sketch of what "professional medical ethics" has become. $^{44}$ Since a provocative paper invites-perhaps incites—a rejoinder, let us take this opportunity to issue to you, the reader, the first of several invitations to you in this editorial to take up your pen in response and send us either correspondence for publication or, perhaps, an article of your own on the question of the medical humanities' institutional "apparatus", and on whether any particular form of it is likely to lead to the humanities being sidelined, so far as professional clinical life and patient care are concerned.

An intimately related question concerns what you might call the "boundary questions" of medical humanities' field of inquiry. What makes an inquiry a medical humanities inquiry? There may of course be no single unifying characteristic, and yet it is tempting to think that something must be at work in bringing together the field's contributory disciplines and writers; and beyond this it is also tempting to think that something must distinguish an interdisciplinary medical humanities question from the "first order" questions arising in its contributor disciplines-questions more straightforwardly arising in ethics, or in medical anthropology, or in history of medicine, or in literature for instance. As for the unifying characteristic, we have elsewhere suggested that if the humanities disciplines in general are linked by a concern to record, to interpret, and understand human experience, then the medical humanities are among other things those same disciplines recording, interpreting, and seeking to understand the human experience of health, illness, disability, and medical and health care. ${ }^{45}$ Perhaps, then, we are doing "medical humanities" when we are attempting precisely this kind of recording, interpreting, understanding - or when we are arguing for it, illuminating it, defining it, or indeed criticising or delimiting or even objecting to it.
Hence our second editorial invitation to you: tell us what you think of such a conception of the medical humanities, and argue-at whatever length you think appropriate-for an alternative conception. We shall be glad to use this invitation as the start for an "open" inquiry of the kind noted above. Relatedly, why not tell us what you think about our implicit presumption that philosophy is a central critical resource for taking up medical humanities inquiries, as our own classification of the journal's published papers suggests? In sticking out our editorial necks and asserting the centrality of philosophy to the medical humanities, let us thirdly invite you to take up the debate by way of reply, perhaps in favour of an alternative "central" contributory discipline, or in favour of their being none at all. Both correspondence and substantial papers are called for!

One alternative view does immediately present itself, of course: still more obviously than philosophy, literary concerns seem centrally engaged with exploring human experience. And literature has a regular presence in the journal through the "Opening the word hoard" and "Medicine through the novel" columns, in addition to the specific groups of papers mentioned above: even papers devoted to educational matters make more reference to literature based teaching than to any other kind. Interestingly, the literary works in question do not need to be directly "medical" in content, even though they often might be; Scott has argued persuasively for the transferability of literary experience from one kind of situation to another. ${ }^{2}$ Again, a presumption in favour of the centrality of literature or philosophy is just that: a presumption (albeit one we would defend). To test it, this journal would be interested in publishing views on the capacity of other disciplines than philosophy or literature for engaging with and conveying human experience.

The educational function of humanities in the medical curriculum is one of the clearest "applications" of medical humanities to the practical institutions of medicine and healthcare; indeed it has been a very evident theme in submitted manuscripts, reflecting its importance and sustaining our regular "Education and debate" column. The general application may be clear-but what are the precise objectives of medical humanities education? We have elsewhere begun to explore these questions, arguing for an important addition to the objectives which were early envisaged in Tomorrow's Doctors $^{46}$ : namely a sense of wonder at embodied human nature. ${ }^{47}$ Here again it may be time to gain a sense of the variety-perhaps, the consensus-of views on this matter from this journal's readers. Hence our fourth invitation to readers is to set out their priorities for the objectives of medical humanities education, and perhaps to consider whether the idea of a "sense of wonder" is something that can legitimately be taught.

Finally, if the educational "application" of medical humanities is clear and widespread, what other aspects of medicine and health care are we in danger of neglecting, if only in relative terms? What reflective and investigational resources does the area of inquiry termed "medical humanities" offer to clinical research, or to the understanding of what one might take to be the "central medical act", the clinical consultation, or to the ongoing management of patients? Some of our previously published papers have approached these questions-in terms of clinical management the areas involved include psychiatric medicine, general practice, care of the elderly, gerontology generally, cosmetic surgery and so forth.

So our fifth (and concluding) invitation, which might in effect be a "call for papers" for a special thematic issue of this journal, is this: what can medical humanities perspectives and inquiries-as distinct from the "therapeutic" use of art media, the so called "arts in health"-most fruitfully contribute to our understanding of the clinical management of patients, and what should be the objectives and priorities for the clinical application of medical humanities? In duly revolutionary spirit this journal will, in the matter of responses to this and the four other invitations issued above, be delighted to follow its readers.

$J$ Med Ethics: Medical Humanities 2003;29: 1-3

\section{Authors' affiliations}

H M Evans, Centre for Arts and Humanities in Health and Medicine, University of Durham, 14/15 Old Elvet, Durham DH1 3HP, UK D A Greaves, Centre for Philosophy and Health Care, School of Health Science, University of Wales Swansea, Singleton Park, Swansea SA2 8PP, UK

Correspondence to: H M Evans; h.m.evans@durham.ac.uk

\section{REFERENCES}

1 Ledru-Rollin A, quoted in de Mirecourt E. Les contemporains: journal critique et biographique [vol 14]. Paris: J.P Roret et Cie, 1854.

2 Scott PA. The relationship between the arts and medicine. J Med Ethics: Medical Humanities 2000;26:3-8.

3 Boyd KM. Disease, illness, sickness, health, healing and wholeness: exploring some elusive concepts. J Med Ethics: Medical Humanities 2000;26:9-17.

4 Saunders J. The practice of clinical medicine as an art and as a science. J Med Ethics: Medical Humanities 2000;26:18-22.

5 Herman J. Medicine: the science and the art. $J$ Med Ethics: Medical Humanities $2001 ; 27: 42-6$. 
6 Holm S. Changes to bodily appearance: the aesthetics of deliberate intervention. J Med Ethics: Medical Humanities 2000;26:43-8

7 Hilhorst MT. Philosophical piffalls in cosmetic surgery: the case of rhinoplasty in adolescence. J Med Ethics: Medical Humanities 2002;28:61-5.

8 Michel LA, Johnson P. Is surgical mystique a myth and double standard the reality? J Medical Ethics: Medical Humanities 2002;28:66-70.

9 Hofmann B. The technological invention of disease. J Med Ethics: Medical Humanities 2001;27:10-19.

10 Fredriksen S. Diseases are invisible. J Med Ethics: Medical Humanities 2002;28:71-3.

11 Warsop A. Art, science and the existential focus of clinical medicine. J Med Ethics: Medical Humanities 2002;28:74-7.

12 Holm S. Does chaos theory have major implications for philosophy of medicine? J Med Ethics: Medical Humanities 2002;28:78-81.

13 Bamforth I. Kafka's uncle: scenes from a world of trust infected by suspicion. J Med Ethics: Medical Humanities 2000;26:85-91.

14 Puustinen R. Voices to be heard: the many positions of a physician in Anton Chekhov's short story A Case History. J Med Ethics: Medical Humanities 2000;26:37-42.

15 Bamforth I. Knock: a study in medical cynicism. J Med Ethics: Medical Humanities 2002;28:14-18.

16 Reed J. A medical perspective on the adventures of Sherlock Holmes. J Med Ethics: Medical Humanities 2001;27:76-81.

17 Shaw AB. Depressive illness delayed Hamlet's revenge. J Med Ethics: Medical Humanities 2002;28:92-6.

18 Platts MM. Some medical syndromes encountered in nineteenth-century French literature. J Med Ethics: Medical Humanities 2001;27:82-8

19 Gore DM. Clinical craft: a lesson from Liverpool. J Med Ethics: Medical Humanities $2001 ; 27: 74-5$

20 Acuña LE. Don't cry for us Argentinians: two decades of teaching medical humanities. $J$
Med Ethics: Medical Humanities 2000;26:66-70

21 Macnaughton J. The humanities in medical education: context, outcomes and structures. J Med Ethics: Medical Humanities 2000;26:23-30.

22 Pickering $\mathbf{N}$. The use of poetry in health care ethics education. J Medical Ethics: Medical Humanities 2000;26:31-6.

23 Ahlzén A, Stolt C-M. Poetry, interpretation and unpredictability: a reply to Pickering. $J$ Med Ethics: Medical Humanities 2001;27:47-9.

24 Richardson R. A necessary inhumanity? [education and debate]. J Med Ethics: Medical Humanities 2000;26:104-6.

25 Francis NR, Lewis W. What price dissection? Dissection literally dissected. 5 Med Ethics: Medical Humanities 2001;27:2-9.

26 Albury WA, Weisz GM. The medical ethics of Erasmus and the physician/patient relationship. J Med Ethics: Medical Humanities 2001;27:35-41.

27 Downie R. Science and the imagination in the age of reason. J Med Ethics: Medical Humanities 2001;27:58-63.

28 Louis-Courvoisier M, Mauron A. "He found me very well: for me, I was still feeling sick": the strange worlds of physicians and patients in the 18th and 21 st centuries. Med Ethics: Medical Humanities 2002;28:9-13.

29 Giordano S. Qu'un souffle de vent: an exploration of anorexia nervosa. J Med Ethics: Medical Humanities 2002;28:3-8.

30 LaCivita Nixon L, Roscoe LA. Anticipating deep autumn: a widening lens. J Med Ethics: Medical Humanities 2002;28:82-7.

31 Sirridge $M$, Welch K. Body image and the innocent eye. J Med Ethics: Medical Humanities 2002;28:35-40.

32 Sayers GM. Of pipes, persons, and patients. $J$ Med Ethics: Medical Humanities 2002;28):88-91.

33 Scher P, Senior P. Research and evaluation of the Exeter Health Care Arts Project. J Med Ethics: Medical Humanities 2000;26:71-8.

34 Turner L. Medical facilities as moral worlds. J Med Ethics: Medical Humanities 2002;28: 19-22.
35 Sweeney KG, Edwards K, Stead J, et al. A comparison of professionals' and patients' understanding of asthma: evidence of emerging dualities? J Med Ethics: Medical Humanities 2001;27:20-5.

36 Kottow M, Kottow A. Literary narrative in medical practice. J Med Ethics: Medical Humanities 2002;28:41-4.

37 Byrne P. The butler(s) DID it-dissociative identity disorder in cinema. J Med Ethics: Medical Humanities 2001;27:26-9.

38 Robinson $\mathbf{M}$. Writing well: health and the power to make images. J Med Ethics: Medical Humanities 2000;26:79-84.

39 Barker P. Working with the metaphor of life and death. J Med Ethics: Medical Humanities 2000;26:97-102.

40 Rowe M. Transplant: a non-fiction narrative. J Medical Ethics: Medical Humanities 2002;28:23-7.

41 Willis J. A personal response to: Zen and the Art of Motorcycle Maintenance by Robert Pirsig. J Med Ethics: Medical Humanities 2000;26:1 10-12.

42 Jay A. A personal response to: The Woman Who Walked Into Doors by Roddy Doyle. J Med Ethics: Medical Humanities 2000;26:58-9

43 Lewis W. "You keep telling me what has been lost, and I keep telling you something remains." A personal response to: Scar Tissue by Michael Ignatieff. J Med Ethics: Medical Humanities 2002;28: 105-6.

44 Pattison S. Medical humanities: a vision and some cautionary notes. J Med Ethics: Medical Humanities 2003;29:xxxxx

45 Evans M. Reflections on the humanities in medical education. Med Educ 2002;36:508-13.

46 General Medical Council. Tomorrow's doctors: recommendations on undergraduate medical education. London: General Medical Council, 1993.

47 Evans M. Roles for literature in medical education. Advances in Psychiatric Treatment 2003. In press. 